\title{
Multiple Major and Minor Anomalies Associated With Klippel-Feil Syndrome: A Case Report
}

\author{
Nada VUJASINOVIC STUPAR, ${ }^{1}$ Slavica PAVLOV-DOLIJANOVIC, ${ }^{1}$ Nur HATIB, ${ }^{2}$ \\ Bojan BANKO, ${ }^{3}$ Milan DJUKIC, ${ }^{4}$ Natasa NIKOLIC JAKOBA ${ }^{5}$ \\ ${ }^{1}$ School of Medicine, University of Belgrade, Institute of Rheumatology, Belgrade, Serbia \\ ${ }^{2}$ Department of Maxillofacial Surgery, School of Dental Medicine, University of Belgrade, Belgrade, Serbia \\ ${ }^{3}$ Clinical Center of Serbia, Center for Radiology and MRI, Belgrade, Serbia \\ ${ }^{4}$ School of Medicine, University of Belgrade, University Childrens Hospital, Belgrade, Serbia \\ ${ }^{5}$ Department of Periodontology and Oral Medicine, School of Dental Medicine, University of Belgrade, Belgrade, Serbia
}

\begin{abstract}
Klippel-Feil syndrome is defined as congenital fusion of two or more cervical vertebrae. In this article, we report a 55-year-old male patient with one-year history of neck pain, headaches, and one episode of syncope after a severe trauma. X-rays and magnetic resonance imaging of cervical spine revealed fused vertebral bodies of C2-C5. The major anomalies associated with Klippel-Feil syndrome (small stature, thoracic kyphoscoliosis, lumbar scoliosis, restricted opening mouth, and bilateral sensorineural hearing loss) as well as multiple minor anomalies (mild face asymmetry, high arched palate, rhinoscoliosis, high nasal bridge, inclined septi nasi, and thin upper lip) were detected. This is a rare case describing the anomalies of the nose in Klippel-Feil syndrome patients. Our patient had no central cord impairment following a severe trauma.

Keywords: Anomalies; Klippel-Feil syndrome; neurological symptoms; trauma.
\end{abstract}

The classic clinical triad of Klippel-Feil syndrome (KFS) -short neck, restricted neck mobility, and low dorsal hairline- is the result of congenital synostosis of a variable number of cervical vertebrae. ${ }^{1}$ Persons with KFS and cervical stenosis may be at increased risk for spinal cord injury after minor trauma as a result of hypermobility of the various cervical segments. Also, clinicians should be aware of the characteristics of KFS when making an oral diagnosis and planning treatment.

In this case report, we described a variation of the KFS, accompanied by anomalies of the cervical vertebrae and other organs. To our knowledge, this is the first KFS diagnosed following a trauma.

\section{CASE REPORT}

A 55-year-old male patient admitted to our clinic because of chronic neck pain, headache, and one episode of syncope. These symptoms with a history of one year started after a trauma when the patient fell off his tractor, and suffered from a fracture of right seventh and eighth ribs.

Patient reported complaints of impaired hearing, snoring, and waking up occasionally with a sense of suffocation and shortness of breath for the last 30 years. He had history of alcohol abuse.

The physical examination revealed a small stature compared to the standard average height for an adult man of Serbian origin $(166 \mathrm{~cm}$ vs. $178 \pm 9 \mathrm{~cm}$, respectively), although his body

Received: July 09, 2015 Accepted: September 29, 2015 Published online: November 02, 2015

Correspondence: Nada Vujasinovic Stupar, MD. School of Medicine, University of Belgrade, Institute of Rheumatology, 11000, Resavska 69 Belgrade, Serbia.

Tel: +38169778441 e-mail: stuparn@eunet.rs

(2016 Turkish League Against Rheumatism. All rights reserved. 
(a)

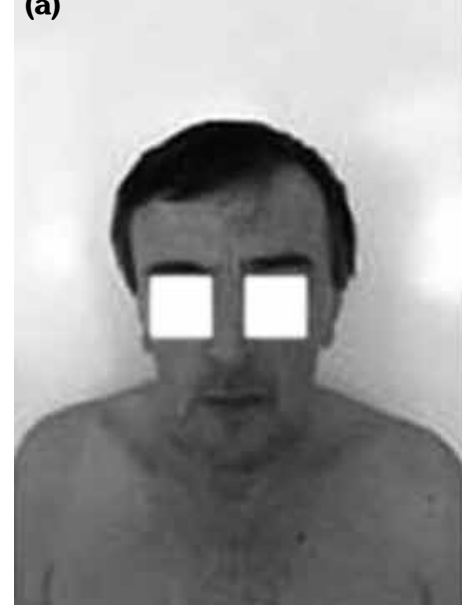

(b)

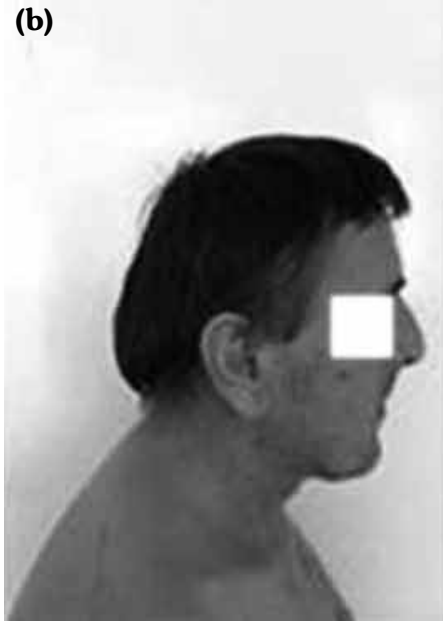

(c)

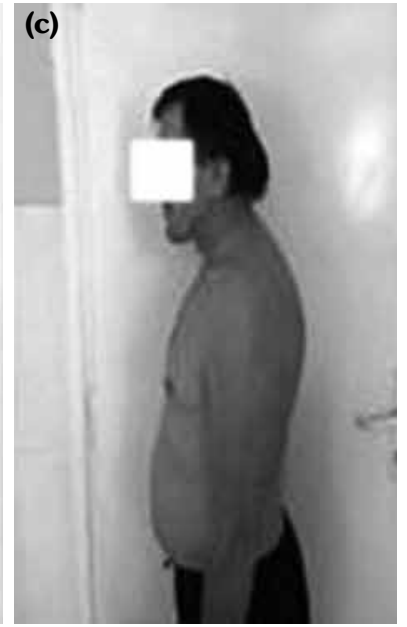

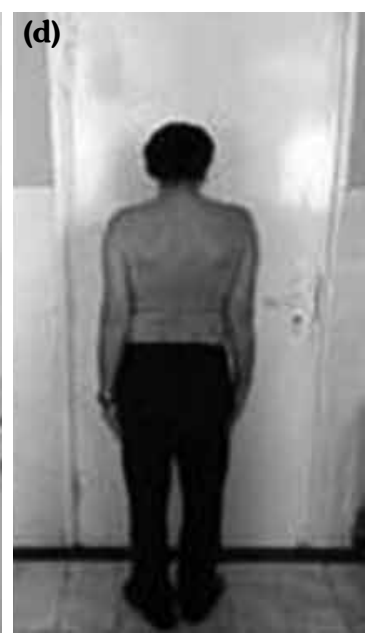

Figure 1. (a) Mild facial asymmetry, (b) high nasal bridge, low posterior hairline, (c) thoracic kyphosis, (d) lumbar scoliosis.

weight was within the standard range for an adult man of the same origin $(77.8 \mathrm{~kg}$ vs. $81.3 \pm 13.9 \mathrm{~kg}$, respectively), ${ }^{2}$ nasal speech, short neck, low posterior hairline, severe limitation of all cervical range of motion, mild face asymmetry, rhinoscoliosis, high nasal bridge, inclined septi nasi, thin upper lip (Figure 1a, b), thoracic kyphoscoliosis, and lumbar scoliosis (Figure 1c, d). Severe periodontitis in nine teeth and high arched palate were detected. The temporomandibular joint examination revealed a bilateral clicking and mouth opening was restricted to $30 \mathrm{~mm}$. The neurological examination, electroencephalography, echocardiography, Doppler neck blood vessels, and all blood and urine analyses were normal.

X-ray examination showed fused $\mathrm{C} 2-\mathrm{C} 5$ vertebral bodies, thoracic kyphoscoliosis, and lumbar scoliosis without other anomalies
(Figure 2a-d). Magnetic resonance imaging revealed posterior partial fusion of $\mathrm{C} 2-\mathrm{C} 5$, hypertrophy of the posterior vertebral elements at levels $\mathrm{C} 5-\mathrm{C} 7$, degenerative disks changes, without sings of cord abnormalities or compression (Figure $2 e, \mathrm{f})$. The audiological assessment showed a moderate to severe bilateral sensorineural hearing loss.

Cone beam computed tomography showed mucosal thickening in the left maxillary sinus due to a chronically maxillary sinusitis (Figure 3a, b) with no other pathological findings (Figure 3c, d). The analyses of the pharyngeal airway showed a narrowing of the pharynx (Figure 4a, b). The volume of pharynx was $32.3 \mathrm{~mL}$, and the area of maximum constriction was $193.6 \mathrm{~mm}^{2}$ (Figure 4c).

Besides KFS, patient was diagnosed with cervical syndrome and cervical discarthrosis.
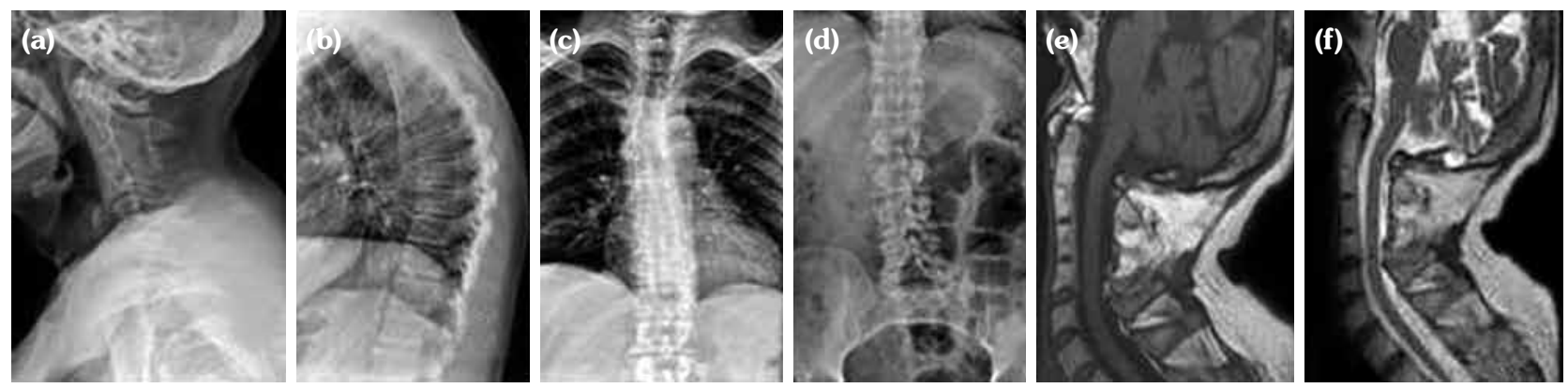

Figure 2. Radiological findings. (a) Congenital fusion of bodies of $\mathrm{C} 2 \mathrm{C} 5$, (b) thoracic spine kyphosis, (c) thoracic scoliosis, (d) lumbar scoliosis, magnetic resonance imaging findings. (e) Partial fusion C2-C5, (f) $\mathrm{T}_{2}$ degenerative changes in discs. 

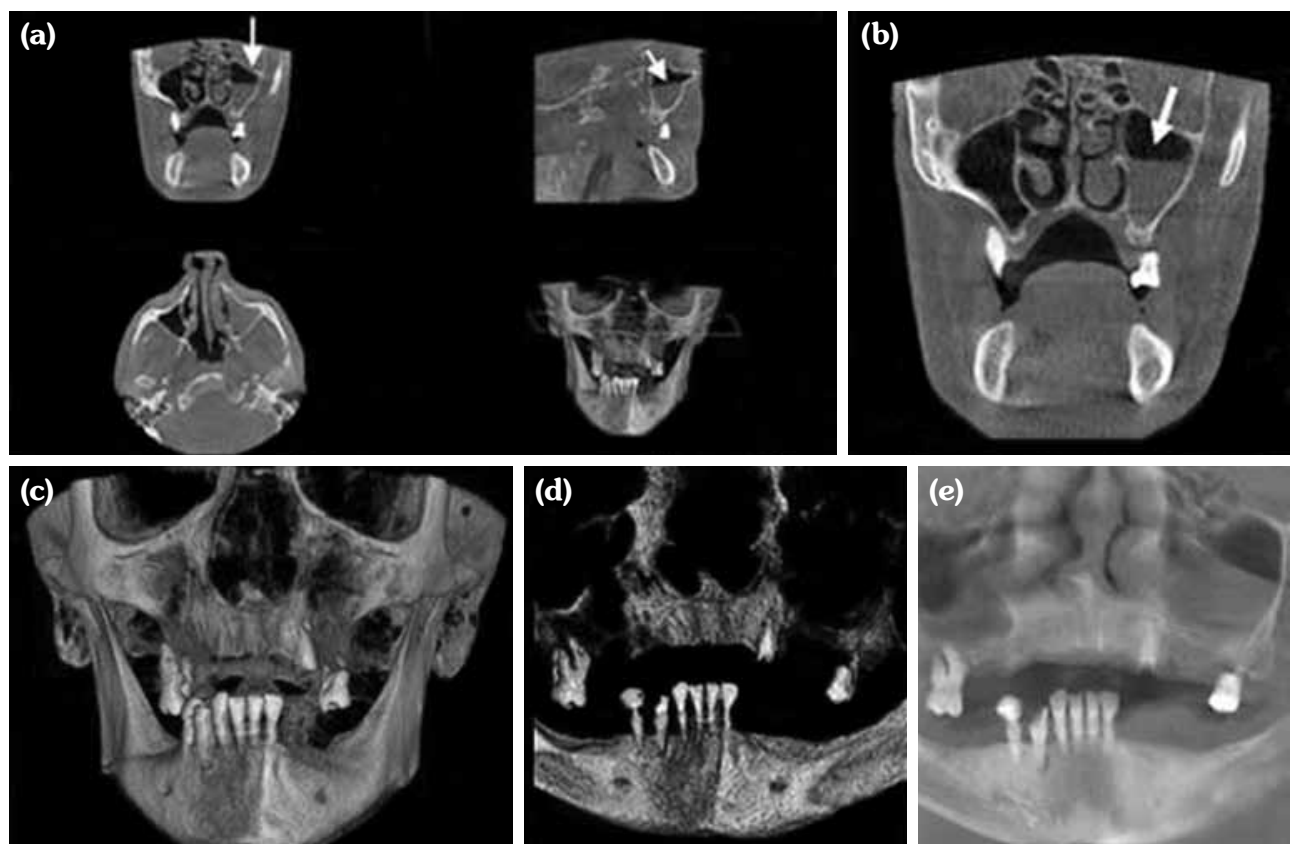

Figure 3. Cone beam computed tomography findings. Chronic maxillary sinusitis with mucosal thickening in left maxillary sinus (white arrows), (a) multi planar view, (b) coronal view, $(\mathbf{c}, \mathbf{d})$ periodontitis mandible and maxillae volume rendering view, $(\boldsymbol{e})$ curved planer view.

The patient was treated with non-steroidal antirheumatic drugs and cervical spine rehabilitation.

\section{DISCUSSION}

There is scarce evidence about KFS, which is described as a rare and little known syndrome, usually diagnosed after birth. ${ }^{3}$ Most KFSs are never diagnosed, probably because the symptoms are bland. ${ }^{4}$ Neurological problems may develop in $27 \%$ of these patients. ${ }^{5}$ However, the age when neurological symptoms appear depend on the level of the cervical fusion. A fusion of $\mathrm{C} 1-\mathrm{C} 2$ tends to produce symptoms in the first decade, while fusion of the C2-C3 is associated with neurological symptoms in the third decade. ${ }^{6}$ However, some reports indicate that the level of vertebrae fusion does not greatly affect the incidence of neurological symptoms. ${ }^{5}$ A defect in level of the occiput to C1-C3 was the most frequently identified and produced most symptoms $(n=462)$. Lesions below C3 and C4 were less likely to cause symptoms. ${ }^{5}$ Our patient had C2-C5 fusion and
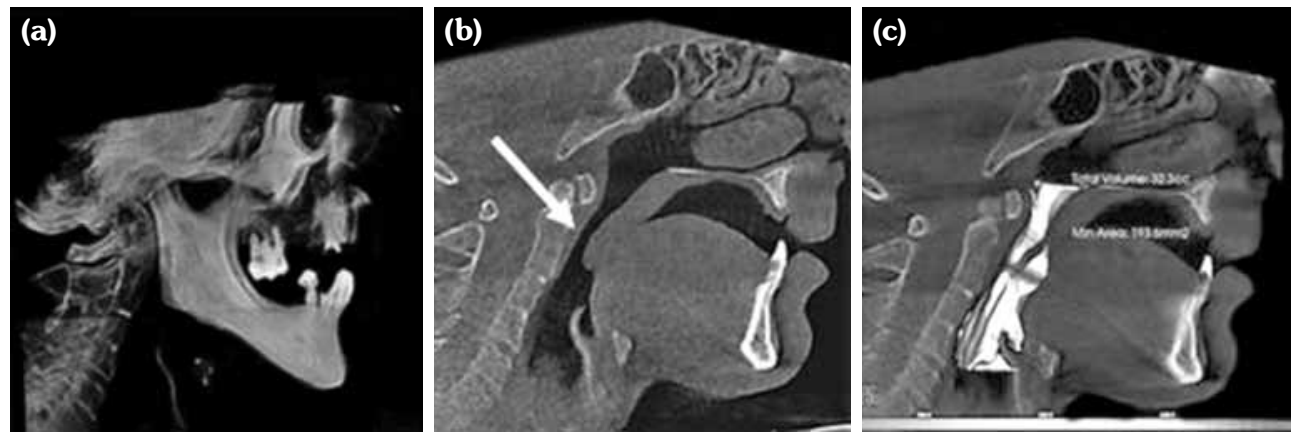

Figure 4. Cone beam computed tomography findings. (a) Narrowing of pharynx volume rendering view, and (b) sagittal view (white arrow), (c) volume rendering reformat, airway volume. 
his symptoms occurred in the sixth decade, after major trauma.

A significant central cord myelopathy after moderate $e^{7}$ or minor ${ }^{8-10}$ traumas were recorded in KFS. This is probably related to the fused segments and the resulting altered mechanical force transfer that makes the adjacent non-fused segments excessively mobile. ${ }^{9,11}$ However, our patient had no central cord impairment after a severe trauma. This can be explained by the absence of hypermobility non-fused spinal segments due to degenerative changes and/or the appearance of neurological symptoms obviously depend on the level of fusion. Our patient was likely to develop a compensatory thoracic-lumbar kyphoscoliosis. Indeed, a review of $50 \mathrm{KFS}$ patients showed an associated scoliosis in 60\%. ${ }^{12}$

A variety of craniofacial anomalies have also been reported in KFS, few of which are quite common, such as cleft palate and bifid uvula (15\%) and facial asymmetry (13\%), whereas others are represented by isolated cases. ${ }^{13}$

Our patient showed mild face asymmetry accompanied by craniofacial anomalies such as rhinoscoliosis, high nasal bridge, inclined septi nasi, thin upper lip, and high arched palate. This patient is a rare KFS case describing nose anomalies. ${ }^{14}$ It is unclear if rhinoscoliosis is a KFS associated anomaly or an independent variable. Further studies are necessary to evaluate if there is a higher incidence of rhinoscoliosis in KFS.

Klippel-Feil syndrome individuals without cleft palate tend to have high arched palate, as detected in our patient. A mandible hypoplasia occurs in a limited number of $\mathrm{KFS}^{15}$ and can contribute to upper airway obstruction and obstructive sleep apnea. Our patient had sleep apnea but no mandible hypoplasia. Even if the volume of the pharynx is in agreement with average measuring, ${ }^{16}$ a narrowing that is found in the level of the maximum constriction can be the cause of obstructive sleep apnea and also of breathing problems. Other causes of his sleep apnea such as chronic sinusitis, snoring, and evening alcohol intake must also be taken into consideration.

Furthermore, our patient was diagnosed as having a moderate to severe bilateral sensorineural hearing loss, the most common (43\%) of hearing problems in KFS. ${ }^{4}$
This case is a good example of a rare characterization of KFS in elderly patients associated with multiple anomalies. Early diagnosis of KFS is critical in determining the risk of other associated diseases and neurological symptoms especially after trauma.

\section{Declaration of conflicting interests}

The authors declared no conflicts of interest with respect to the authorship and/or publication of this article.

\section{Funding}

The authors received no financial support for the research and/or authorship of this article.

\section{REFERENCES}

1. González-Reimers E, Mas-Pascual A, Arnay-De-LaRosa M, Velasco-Vásquez J, Jiménez-Gómez MC. Klippel-Feil syndrome in the prehispanic population of El Hierro (Canary Islands). Ann Rheum Dis 2001;60:174.

2. Available from: http://www.tnsmediumgallup.co.rs/ newsletters/Zivimo\%20zdravije_IZVESTAJ\%20 ZA\%20MEDIJE_print.pdf

3. Boraz RA, Irwin DH, Van Blarcom C. The dental rehabilitation of a patient with Klippel-Feil syndrome and Sprengel's deformity. Spec Care Dentist 1986;6:22-4.

4. Thomsen MN, Schneider U, Weber M, Johannisson R, Niethard FU. Scoliosis and congenital anomalies associated with Klippel-Feil syndrome types I-III. Spine (Phila Pa 1976) 1997;22:396-401.

5. Gray SW, Romaine CB, Skandalakis JE. Congenital fusion of the cervical vertebrae. Surg Gynecol Obstet 1964;118:373-85.

6. Helmi C, Pruzansky S. Craniofacial and extracranial malformations in the Klippel-Feil syndrome. Cleft Palate J 1980;17:65-88.

7. O'Donnel DP, Seupaul RA. Klippel-Feil syndrome. Am J Emerg Med 2008;26:252.e1-2.

8. Vaidyanathan S, Hughes PL, Soni BM, Singh G, Sett $P$. Klippel-Feil syndrome - the risk of cervical spinal cord injury: a case report. BMC Fam Pract 2002;3:6.

9. Strax TE, Baran E. Traumatic quadriplegia associated with Klippel-Feil syndrome: discussion and case reports. Arch Phys Med Rehabil 1975;56:363-5.

10. Adeleye AO, Akinyemi RO. Cervical Klippel-Feil syndrome predisposing an elderly African man to central cord myelopathy following minor trauma. Afr Health Sci 2010;10:302-4.

11. Woon CY, Chong KC, Teh, HS, Lee HC. Cervical spine trauma in Klippel-Feil syndrome: Two cases with contrasting outcomes and a review of the literature. 
Injury Extra 2007;38:392-6.

12. Hensinger RN, Lang JE, MacEwen GD. Klippel-Feil syndrome; a constellation of associated anomalies. J Bone Joint Surg Am 1974;56:1246-53.

13. Naikmasur VG, Sattur AP, Kirty RN, Thakur AR. Type III Klippel-Feil syndrome: case report and review of associated craniofacial anomalies. Odontology 2011;99:197-202.

14. Fragoso R, Cid-García A, Hernández A, Nazará Z, Cantú JM. Frontonasal dysplasia in the Klippel-Feil syndrome: a new associated malformation. Clin Genet 1982;22:270-3

15. Dave N, Sharma RK, Andrade NN. Anaesthesia for retrognathia correction in a case of Klippel Feil syndrome. Indian J Anaesth 2006;50:128-30.

16. Grauer D, Cevidanes LS, Styner MA, Ackerman JL, Proffit WR. Pharyngeal airway volume and shape from cone-beam computed tomography: relationship to facial morphology. Am J Orthod Dentofacial Orthop 2009;136:805-14. 